\title{
An Investigation of the Miscibility Gap Controlling Phase Formation in Refractory Metal High Entropy Superalloys via the Ti-Nb-Zr Constituent System
}

\author{
Tamsin E. Whitfield ${ }^{1}\left(\mathbb{D}\right.$, George J. Wise ${ }^{1}\left(\mathbb{D}\right.$, Ed J. Pickering $^{2}{ }^{(}$, Howard J. Stone $^{1}\left(\mathbb{D}\right.$ and Nicholas G. Jones ${ }^{1, *(D)}$ \\ 1 Department of Materials Science and Metallurgy, University of Cambridge, Cambridge CB3 OFS, UK; \\ tw398@cam.ac.uk (T.E.W.); gjw41@cam.ac.uk (G.J.W.); hjs1002@cam.ac.uk (H.J.S.) \\ 2 Department of Materials, Henry Royce Institute, University of Manchester, Manchester M1 3BB, UK; \\ ed.pickering@manchester.ac.uk \\ * Correspondence: ngj22@cam.ac.uk; Tel.: +44-1223334367
}

\section{check for} updates

Citation: Whitfield, T.E.; Wise, G.J.; Pickering, E.J.; Stone, H.J.; Jones, N.G. An Investigation of the Miscibility Gap Controlling Phase Formation in Refractory Metal High Entropy Superalloys via the Ti-Nb-Zr Constituent System. Metals 2021, 11, 1244. https://doi.org/10.3390/ met11081244

Academic Editor:

Alexander Kauffmann

Received: 29 June 2021

Accepted: 29 July 2021

Published: 5 August 2021

Publisher's Note: MDPI stays neutral with regard to jurisdictional claims in published maps and institutional affiliations.

Copyright: (c) 2021 by the authors. Licensee MDPI, Basel, Switzerland. This article is an open access article distributed under the terms and conditions of the Creative Commons Attribution (CC BY) license (https:/ / creativecommons.org/licenses/by/ $4.0 /)$.

\begin{abstract}
Refractory metal high entropy superalloys (RSAs) have been heralded as potential new high temperature structural materials. They have nanoscale cuboidal bcc $+\mathrm{B} 2$ microstructures that are thought to form on quenching through a spinodal decomposition process driven by the Ta- $\mathrm{Zr}$ or $\mathrm{Nb}-\mathrm{Zr}$ miscibility gaps, followed by ordering of one of the bcc phases. However, it is difficult to isolate the role of different elemental interactions within compositionally complex RSAs. Therefore, in this work the microstructures produced by the $\mathrm{Nb}-\mathrm{Zr}$ miscibility gap within the compositionally simpler $\mathrm{Ti}-\mathrm{Nb}-\mathrm{Zr}$ constituent system were investigated. A systematic series of alloys with compositions of $\mathrm{Ti}_{5 \mathrm{Nb}} \mathrm{Zr}_{95-\mathrm{x}}(\mathrm{x}=25-85$ at.\%) was studied following quenching from solution heat treatment and long duration thermal exposures at 1000,900 and $700{ }^{\circ} \mathrm{C}$ for $1000 \mathrm{~h}$. During exposures at $900{ }^{\circ} \mathrm{C}$ and above the alloys resided in a single bcc phase field. At $700{ }^{\circ} \mathrm{C}$, alloys with $40-75$ at. $\% \mathrm{Nb}$ resided within a three phase $b c c+b c c+$ hcp phase field and a large misfit, $4.7-5 \%$, was present between the two bcc phases. Evidence of nanoscale cuboidal microstructures was not observed, even in slow cooled samples. Whilst it was not possible to conclusively determine whether a spinodal decomposition occurs within this ternary system, these insights suggest that $\mathrm{Nb}-\mathrm{Zr}$ interactions may not play a significant role in the formation of the nanoscale cuboidal RSA microstructures during cooling.
\end{abstract}

Keywords: refractory alloys; high entropy alloys; complex concentrated alloys; spinodal decomposition; lattice misfit; microstructure

\section{Introduction}

Refractory metal high entropy superalloys (RSAs), which are a group of alloys developed from the high entropy alloy (HEA) compositional premise, have shown promise as novel high temperature materials. They comprise combinations of mutually soluble bcc refractory metals, such as $\mathrm{Mo}, \mathrm{Nb}$ and $\mathrm{Ta}$ that have high melting points, along with lighter elements such as $\mathrm{Ti}, \mathrm{Zr}$ and $\mathrm{Al}$, the latter of which can induce B2 ordering. These alloys have demonstrated greater high temperature compressive strengths and lower densities than several commonly used polycrystalline Ni-based superalloys [1,2]. The impressive high temperature strengths were thought to be derived from the dual phase intergranular microstructure comprising nanoscale cuboidal and plate-like bcc precipitates within an ordered B2 superlattice matrix [2-6]. This fine-scale, ordered/disordered microstructure has drawn comparisons to the $\gamma-\gamma^{\prime}$ microstructure of Ni-based superalloys, despite the bcc basis of RSAs distinguishing them from the fcc-based Ni-based superalloys [2-6]. Critically, the microstructural configuration of the ordered and disordered phases in RSAs are inverse to that found in Ni-based superalloys, with an ordered B2 matrix phase, which is a concern for the room temperature ductility. Nevertheless, given the morphological and 
crystallographic similarities between the two phases in RSAs, it has been suggested that they may be able to exploit similar strengthening mechanisms that have led to the success of Ni-based superalloys in high temperature applications. However, despite significant global research activity, several key challenges remain in the development of commercially viable RSAs. Among these challenges, it is generally accepted that greater control over the microstructural formation is required in order to produce materials with a ductile bcc matrix phase and stable superlattice precipitates [2,5,7-12].

The nano-scale microstructures in RSAs are believed to form via a spinodal decomposition during cooling to produce two coherent bcc phases, one of which undergoes an ordering transition to form the B2 phase $[5,8,10,13,14]$. Spinodal decomposition occurs when the second derivative of the Gibbs energy curve with composition within a miscibility gap is negative. This allows progressive phase separation to occur by uphill diffusion. Within the constituent binary and ternary systems of RSAs there are multiple bcc + bcc miscibility gaps, including $\mathrm{Ta}-\mathrm{Zr}, \mathrm{Nb}-\mathrm{Zr}$ and $\mathrm{Mo}-\mathrm{Ti}-\mathrm{Zr}$, which have the potential to contribute to the formation of the nanoscale microstructures observed in RSAs. It should be noted that the Mo-Zr binary system does not contain a miscibility gap due to the formation of the $\mathrm{Mo}_{2} \mathrm{Zr}$ laves phase. Detailed analysis of the fine two-phase microstructure of the exemplar RSA, $\mathrm{AlMo}_{0.5} \mathrm{NbTa}_{0.5} \mathrm{TiZr}$, has shown the $\mathrm{B} 2$ matrix phase to be enriched in $\mathrm{Al}$ and $\mathrm{Zr}$, whilst the bcc regions were richer in the refractory components $\mathrm{Nb}, \mathrm{Mo}$, and $\mathrm{Ta}[1,3]$. The Ti content was very similar between the two phases, with a slight preference for the $\mathrm{Zr}$ and $\mathrm{Al}$-rich phase. Consequently, it has been proposed that the formation of the two-phase microstructure in $\mathrm{AlMo}_{0.5} \mathrm{NbTa}_{0.5} \mathrm{TiZr}$ is driven by the miscibility gaps between the refractory metals, particularly $\mathrm{Ta}$ or $\mathrm{Nb}$, and $\mathrm{Zr}$ [5].

However, it should be noted that significant variation occurs in the temperature and composition range of the $\mathrm{bcc}+\mathrm{bcc}$ miscibility gaps in refractory metal-Zr systems. The binary Ta-Zr miscibility gap extends up to $\sim 1783^{\circ} \mathrm{C}$, whilst the $\mathrm{Nb}-\mathrm{Zr}$ miscibility gap is present only below $\sim 988^{\circ} \mathrm{C}[15,16]$. Consequently, the thermodynamic driving force for spinodal decomposition is likely to be greater in the Ta-Zr system than in the $\mathrm{Nb}-\mathrm{Zr}$ system. A recent study of the Ta-Ti-Zr constituent RSA system demonstrated that the Ta-Zr miscibility gap produces nano-scale cuboidal RSA morphologies through spinodal decomposition [10]. However, given the wide variation in the extent of refractory metal-Zr miscibility gaps, it is not known whether similar microstructures can result from other refractory metal-Zr interactions. Crucially, a greater understanding of the effect of the interactions of different refractory elements on the microstructure of RSAs is necessary to aid the design of future alloys with optimised properties.

Isolating the effects of individual elements within RSAs is challenging due to the inherent compositional complexity of these materials. One approach to mitigate this is to investigate simplified constituent systems that behave in a similar manner to the multicomponent alloys. Recently, this approach has been used to study the influence of the Ta-Zr miscibility gap on the phase morphologies observed in RSAs and to assess the role of $\mathrm{Al}$ in the formation of the ordered B2 structure [10,13]. A similar approach is adopted here, where a systematic series of alloys from the $\mathrm{Nb}$-Ti-Zr system have been used to study the role of the $\mathrm{Nb}-\mathrm{Zr}$ miscibility gap on microstructural development. Existing ternary phase diagrams indicate that a miscibility gap exists within the $\mathrm{Nb}$-Ti-Zr system [17-21] and potential spinodal microstructures have been observed in an equiatomic alloy [22] However, there are significant variations between the phase diagrams produced by these different studies, particularly with respect to the temperature and composition ranges over which the miscibility gap exists. Consequently, it is crucial to resolve these discrepancies in order to develop a better understanding of how elemental contributions may influence the microstructural formation and evolution in the more complex RSAs.

\section{Methods}

A series of alloys, with a systematically varying ratio of $\mathrm{Nb}$ to $\mathrm{Zr}$ and a fixed $\mathrm{Ti}$ content of 5 at.\% were produced via arc melting from elemental metals ( $\geq 99.5 \%$ purity). The 
nominal compositions of the alloys were $5 \mathrm{Ti}-25 \mathrm{Nb}-70 \mathrm{Zr}$, $5 \mathrm{Ti}-40 \mathrm{Nb}-55 \mathrm{Zr}$, $5 \mathrm{Ti}-55 \mathrm{Nb}-40 \mathrm{Zr}$, $5 \mathrm{Ti}-$ $70 \mathrm{Nb}-25 \mathrm{Zr}, 5 \mathrm{Ti}-85 \mathrm{Nb}-10 \mathrm{Zr}$ at. $\%$ and, from here onwards, these materials will be referred as Alloy 2570, Alloy 4055, Alloy 5540, Alloy 7025 and Alloy 8510, respectively. These compositions were selected as they spanned the miscibility gap in predicted ternary phase diagrams, as shown in Figure 1. Each alloy was melted under an inert Ar atmosphere, which had been pre-gettered by melting an ingot of pure Ti. To increase homogeneity across the dimensions of the bar, each ingot was inverted and re-melted a total of eight times. Following melting, the ingots, each of $\sim 70 \times 12 \times 8 \mathrm{~mm}$, were solution heat treated at $1200{ }^{\circ} \mathrm{C}$ for $100 \mathrm{~h}$. Certified X-ray Fluorescence Spectroscopy (XRF) and fusion-thermal conductivity methods (LECO), at an external laboratory, were used on solution heat treated material to determine the actual composition of the alloys produced. Further long duration thermal exposures were conducted on $\sim 10 \mathrm{~mm}$ sections taken along the length of the solution heat treated bar at temperatures of 1000,900 and $700{ }^{\circ} \mathrm{C}$ for $1000 \mathrm{~h}$. In each case, the samples for thermal exposure were wrapped in a Ta foil getter, sealed under vacuum in quartz tubes, and the heat treatments concluded with an ice-water quench.
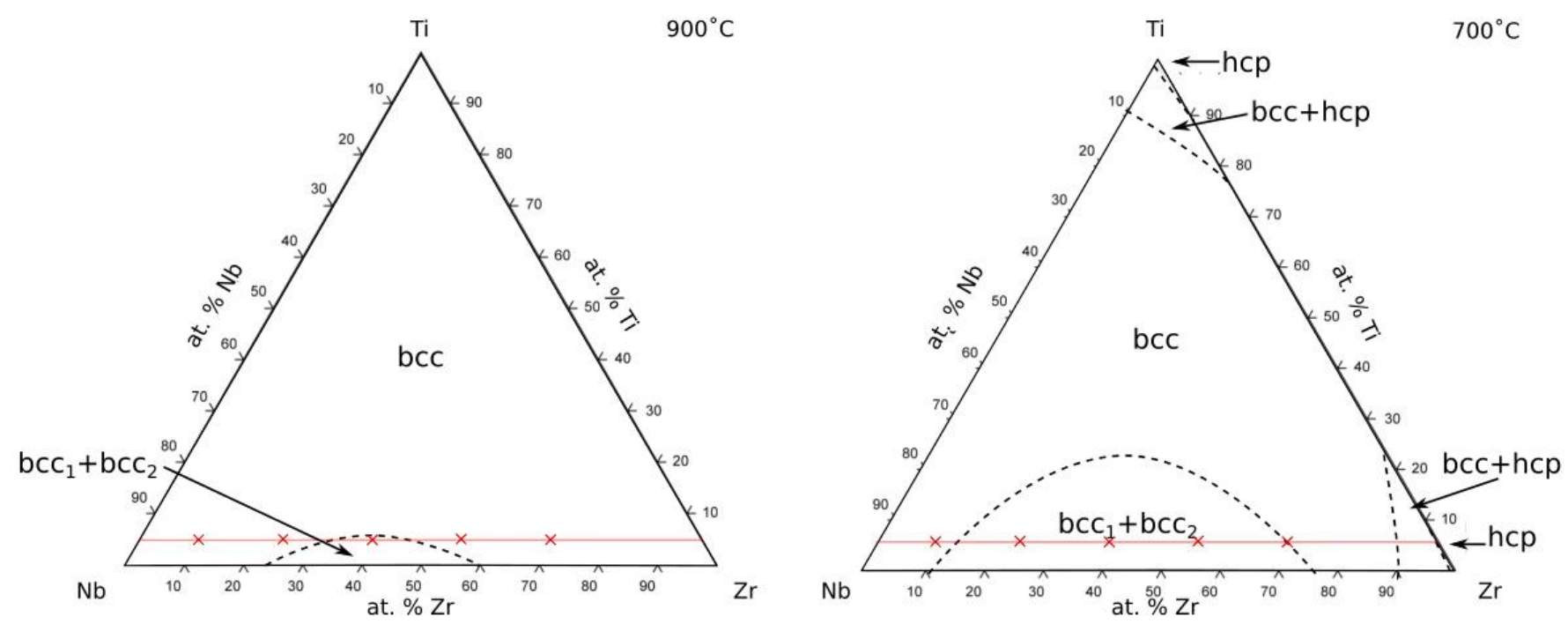

Figure 1. Predicted Ti-Ta-Zr phase diagram at $900{ }^{\circ} \mathrm{C}$ and $700{ }^{\circ} \mathrm{C}$ (adapted from [20]) with the nominal composition of the alloys investigated in this study superimposed as red crosses. The red lines indicate the fixed Ti content of the alloys studied.

Samples from each microstructural condition were prepared for scanning electron microscopy (SEM) analysis by standard metallographic techniques, concluding by polishing with a buffered solution of $0.06 \mu \mathrm{m}$ colloidal silica. Characterisation of the microstructures was primarily conducted using back scattered electron (BSE) imaging on a Nova NanoSEM 450 SEM (FEI, Thermo Fisher Scientific, Hillsboro, OR, USA) and a GeminiSEM 300 (Carl Zeiss Microscopy, Jena, Thuringia, Germany), both operated at $20 \mathrm{kV}$. Elemental distribution maps were obtained via an X-MaxN 50 energy dispersive X-ray (EDX) detector (Oxford Instruments, Abingdon, Oxfordshire, UK) in the Zeiss SEM. Information regarding the crystallography was obtained through X-ray diffraction (XRD), performed with a D8 diffractometer (Bruker, Billerica, MA, USA) across $10-130^{\circ} 2 \theta$ using Ni filtered Cu radiation. Phase identification and lattice parameters were obtained by whole pattern refinement of the diffraction data using the Pawley method in the TOPAS-Academic software (Coelho Software, Brisbane, Australia).

Imaging of the fine-scale microstructural features present within the microstructures and higher resolution analysis was carried out using Transmission Electron Microscopy (TEM). Electron transparent foils were extracted using an FEI Helios dual-beam focused ion beam (FIB) instrument and were studied in an FEI Talos F200X Scanning Transmission Electron Microscope (STEM), equipped with Super EDX detectors and operated at 
$200 \mathrm{kV}$. STEM-EDX quantification was performed using Thermo Scientific Velox software (version 3.0.0.815).

\section{Results}

\subsection{As-Cast and Solution Heat Treated Condition Material}

Following arc melting, all of the alloys exhibited slight dendritic microsegregation, with $\mathrm{Nb}$ rich dendrites and $\mathrm{Zr}$ rich interdendritic regions. Following solution heat treatment at $1200{ }^{\circ} \mathrm{C}$ for $100 \mathrm{~h}$, the EDX elemental distribution maps demonstrated an even distribution of the constituent elements, to the resolution limits of the instrument, indicating that the heat treatment was sufficient to homogenise all of the alloys studied. In the solution heat treated condition no evidence of secondary phases was observed within the microstructures of any of the alloys, at least to the resolution limit of the images obtained $(\sim 10 \mathrm{~nm})$. Bulk compositional analysis of the experimental alloys was performed following solution heat treatment using certified methodologies at an external laboratory. The measured compositions, including oxygen concentrations for the alloys, are shown in Table 1. All of the alloys were found to be close to their nominal compositions with oxygen concentrations comparable to that in other studies [10].

Table 1. Measured alloy compositions, determined by XRF and fusion-thermal conductivity.

\begin{tabular}{cccccc}
\hline Alloy & $\begin{array}{c}\text { Alloy } \\
\text { Designation }\end{array}$ & Ti (at.\%) & Nb (at.\%) & Zr (at.\%) & O (at.\%) \\
\hline Ti-25Nb-70Zr & Alloy 2570 & 5.0 & 22.9 & 71.7 & 0.4 \\
Ti-40Nb-55Zr & Alloy 4055 & 5.0 & 40.2 & 54.5 & 0.3 \\
Ti-55Nb-40Zr & Alloy 5540 & 5.0 & 55.6 & 39.2 & 0.2 \\
Ti-70Nb-25Zr & Alloy 7025 & 4.9 & 70.1 & 24.7 & 0.3 \\
Ti-85Nb-10Zr & Alloy 8510 & 4.5 & 86.4 & 8.9 & 0.2 \\
\hline
\end{tabular}

X-ray diffraction patterns for each of the alloys in the solutioned condition are shown in Figure 2. The patterns corresponded to bcc structures in each of the alloys, with no other peaks visible above the background. However, asymmetric peak profiles were evident at high angles, particularly in the samples with greater $\mathrm{Nb}$ contents, Alloys 5540, 7520 and 8510. Such asymmetry might imply the presence of an additional phase within the microstructures of these alloys. In each case, the lattice parameters were obtained by full pattern refinement using the Pawley method in TOPAS-Academic, as shown in Table 2. These refined lattice parameters indicated that the size of the bcc unit cells were strongly affected by the ratio of $\mathrm{Nb}$ to $\mathrm{Zr}$ in the alloy. Alloys with greater $\mathrm{Zr}$ concentrations had larger lattice parameters, consistent with the trend reported in a series of $\mathrm{Ti}-24 \mathrm{Nb}-\mathrm{xZr}$ alloys [23]. In the study by Pang et al. [23], the lattice parameter increase was seen to be roughly proportional to $\mathrm{Zr}$ content and the lattice parameter of Alloy 2570 is consistent with extrapolating this data to 70 at.\% Zr. This trend is in line with the principle of Vegard's law, but the lattice parameters do not agree precisely with those expected from a rule of mixtures prediction based on the individual elements. 


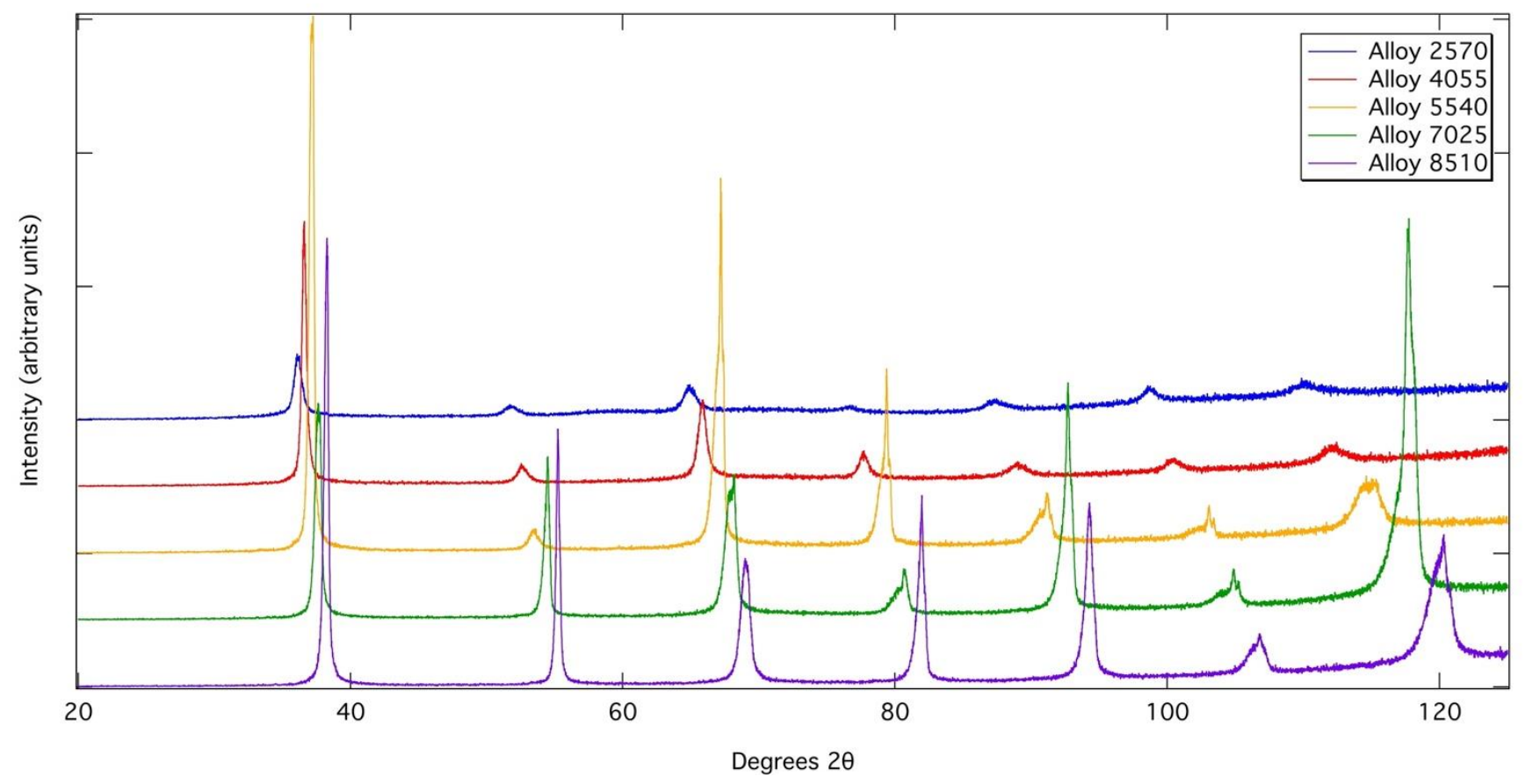

Figure 2. X-ray diffraction patterns obtained from each alloy after solution heat treatment solutioned.

Table 2. Lattice parameters of the phases present in all of the alloys studied in the solution heat treated condition.

\begin{tabular}{|c|c|c|}
\hline Alloy & Lattice Parameter of $\mathrm{bcc}_{1}(\AA)$ & Lattice Parameter of $\mathrm{bcc}_{2}(\AA)$ \\
\hline \multicolumn{3}{|l|}{ Solutioned } \\
\hline Alloy 2570 & 3.52 & - \\
\hline Alloy 4055 & 3.47 & - \\
\hline Alloy 5540 & 3.41 & - \\
\hline Alloy 7025 & 3.38 & - \\
\hline Alloy 8510 & 3.33 & - \\
\hline \multicolumn{3}{|l|}{$1000^{\circ} \mathrm{C}$} \\
\hline Alloy 2570 & 3.53 & - \\
\hline Alloy 4055 & 3.47 & - \\
\hline Alloy 5540 & 3.40 & - \\
\hline Alloy 7025 & 3.38 & - \\
\hline Alloy 8510 & 3.33 & - \\
\hline \multicolumn{3}{|l|}{$900^{\circ} \mathrm{C}$} \\
\hline Alloy 2570 & 3.52 & - \\
\hline Alloy 4055 & 3.46 & - \\
\hline Alloy 5540 & 3.42 & - \\
\hline Alloy 7025 & 3.37 & - \\
\hline Alloy 8510 & 3.33 & - \\
\hline \multicolumn{3}{|l|}{$700^{\circ} \mathrm{C}$} \\
\hline Alloy 2570 & 3.52 & - \\
\hline Alloy 4055 & 3.34 & 3.51 \\
\hline Alloy 5540 & 3.34 & 3.51 \\
\hline Alloy 7025 & 3.34 & 3.50 \\
\hline Alloy 8510 & 3.33 & - \\
\hline
\end{tabular}

However, unlike the diffraction data, BSE SEM images of all of the alloys exhibited an even contrast, Figure 3, which again was maintained to the resolution limit of the SEM $(\sim 10 \mathrm{~nm})$. Such an observation is markedly different from the microstructures obtained from alloys in the miscibility gaps reported in the Ta-Ti-Zr and Al-Ta-Ti-Zr systems, as well 
as complex RSAs, which all contain 5-25 nm particles that can be observed clearly in an SEM $[1,10,13]$. Furthermore, the intragranular microstructures of samples from each of the alloys heated above $1200{ }^{\circ} \mathrm{C}$ and cooled slowly $\left(\right.$ at $10{ }^{\circ} \mathrm{C} / \mathrm{min}$ ) also remained featureless, with no indication of phase decomposition observed within the resolution limits of the microscope. As such, if the Alloys 5540, 7025 and 8510 do contain two phases, as suggested by the diffraction data, then these features must be present at an extremely fine length scale. Thus, it is clear that the second phase must have formed during cooling, rather than being present at the exposure temperature.

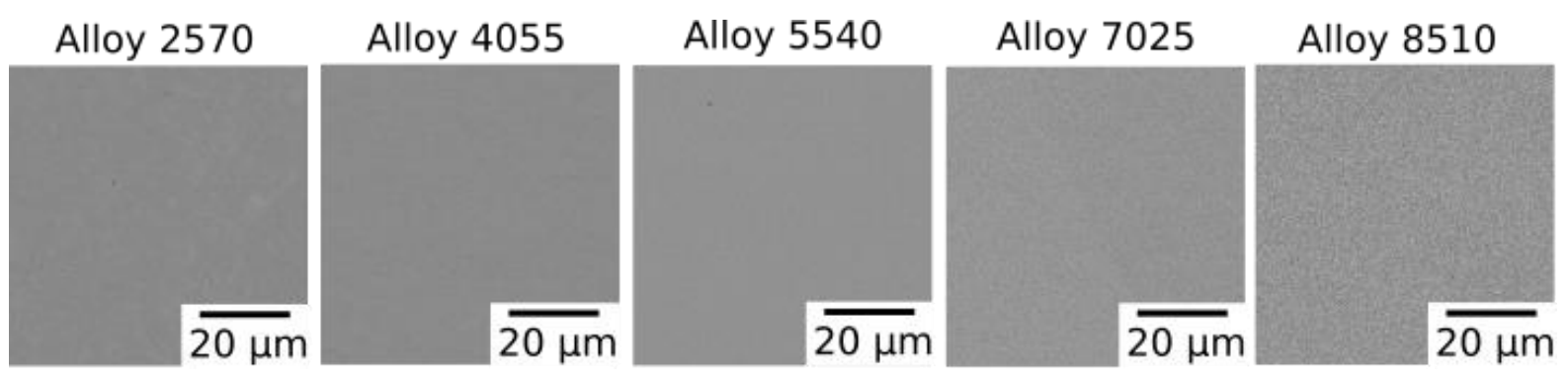

Figure 3. BSE images of each of the alloys in the solutioned condition.

\subsection{Thermally Exposed Material}

BSE micrographs of each of the alloys following long duration exposure at 1000, 900 and $700{ }^{\circ} \mathrm{C}$ for $1000 \mathrm{~h}$ are presented in Figure 4. Existing phase diagrams, for example those presented in Figure 1, suggest that at temperatures above $900{ }^{\circ} \mathrm{C}$ all the alloys would be in a single bcc phase field, whilst at $900{ }^{\circ} \mathrm{C}$ Alloy 5540 would be located in a two-phase field. Following exposure at $1000{ }^{\circ} \mathrm{C}$ for $1000 \mathrm{~h}$ the micrographs of all the alloys, Figure 4, consisted of equiaxed grains with an even BSE contrast, similar to those in the solutioned condition and consistent with the phase diagrams. However, following exposure at $900{ }^{\circ} \mathrm{C}$ all the alloys remained predominantly single phase, Figure 4 . Although, some grain boundary and intragranular particles were observed in alloys 5540, 7025 and 8510 particularly near the sample surface. A typical example of these particles is presented in Figure 5, and the corresponding EDX data indicated these features were enriched in $\mathrm{Zr}$ and $\mathrm{O}$. As such, these particles are thought to arise from $\mathrm{O}$ contamination and are not believed to reflect the phase equilibria of the Ti-Nb-Zr system.

At $700{ }^{\circ} \mathrm{C}$, current phase diagrams suggest that Alloys 2570, 4055, 5540, and 7025 would reside within a bcc + bcc two-phase field, whilst Alloy 8510 would lie within a single bcc phase field. However, following a $1000 \mathrm{~h}$ exposure at $700^{\circ} \mathrm{C}$, Figure 4, only Alloys 4055, 5540 and 7025 exhibited multiphase microstructures. These microstructures featured fine intragranular lamellar structures that consisted of three phases. In contrast to the phase diagram, Alloy 2570 appeared to consist of only one phase. Alloy 8510, predominantly comprised a single phase, though some dark BSE contrast grain boundary precipitates were observed, particularly near the sample surface. As these precipitates were enriched in $\mathrm{O}$, like those observed at $900^{\circ} \mathrm{C}$, and found near the sample surface they are believed to arise from $\mathrm{O}$ contamination rather than corresponding to the phase equilibria studied herein.

As such, there appear to be some discrepancies in the position of the solvus line, which bounds the single phase field, between phase diagrams predicted by Lin et al. [20] and the experimental results obtained here. Consequently, further characterization of the microstructures obtained following exposure at 1000,900 and $700{ }^{\circ} \mathrm{C}$ were performed in order to determine the nature of the constituent phases. 

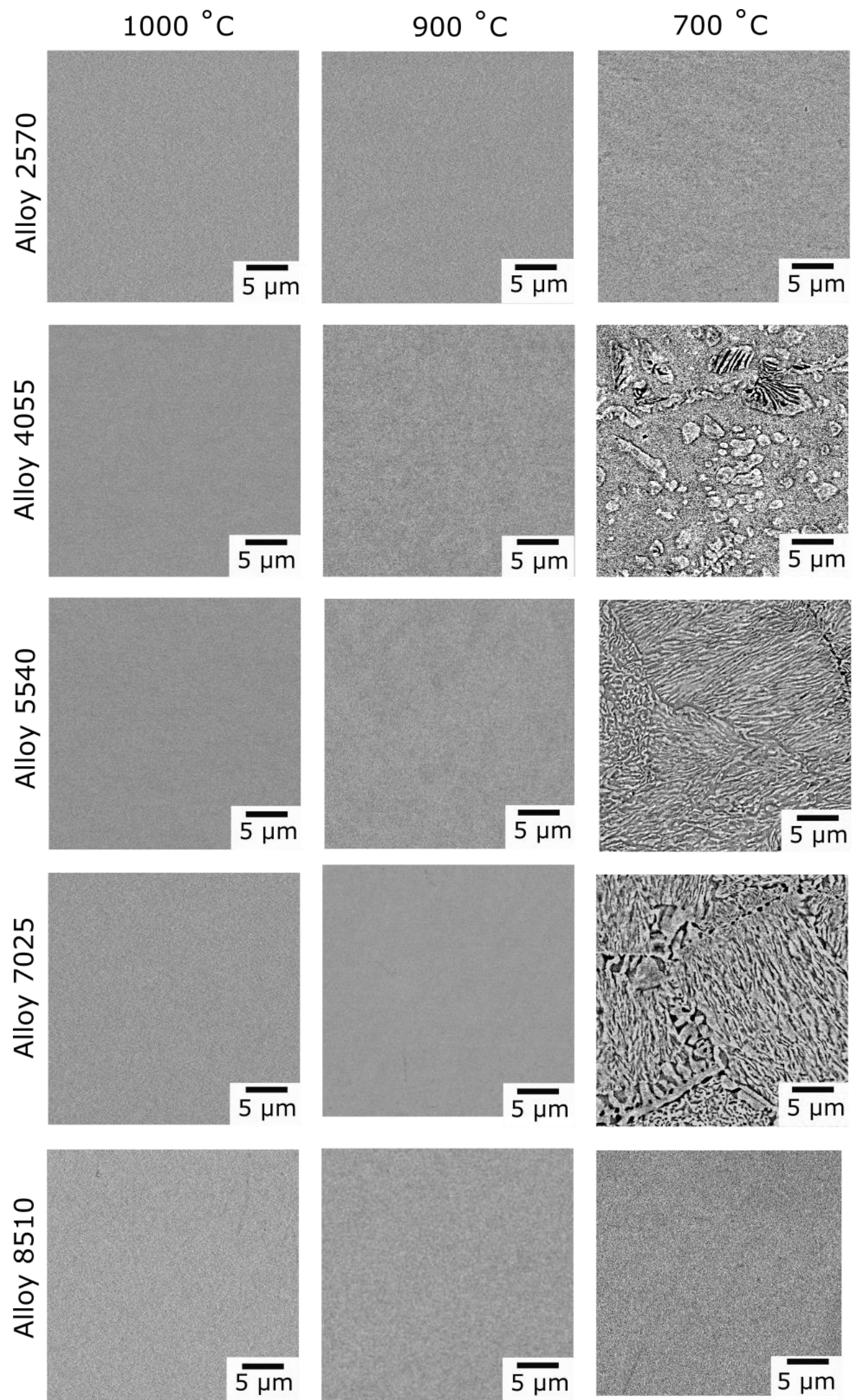

Figure 4. BSE images of Alloys 2570 (Ti-25Nb-70Zr at.\%), 4055 (Ti-40Nb-55Zr at.\%), 5540 (Ti-55Nb$40 \mathrm{Zr}$ at.\%), 7025 (Ti-70Nb-25Zr at.\%), and 8510 (Ti-85Nb-10Zr at.\%) following exposure at 1000, 900 and $700{ }^{\circ} \mathrm{C}$ for $1000 \mathrm{~h}$. 

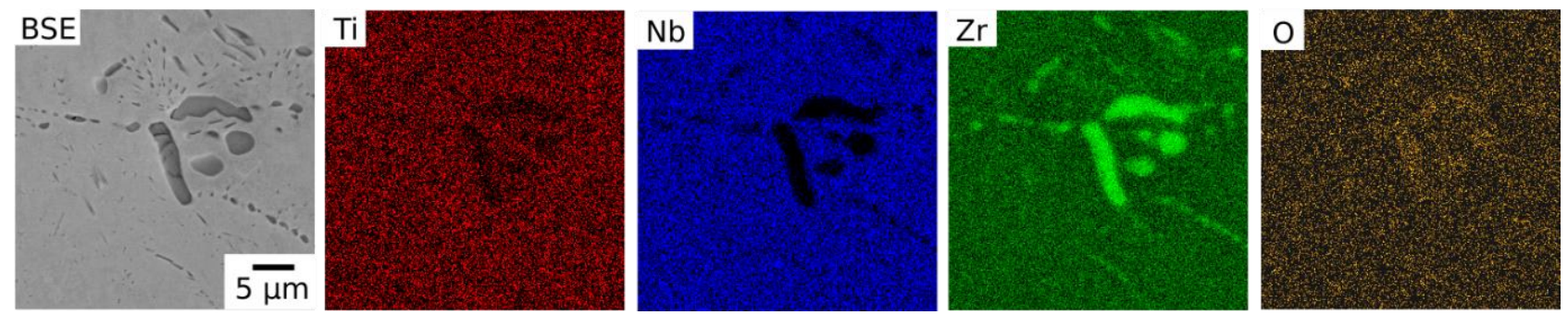

Figure 5. BSE image of a grain boundary region in Alloy 7025 (Ti-70Nb-25Zr at.\%) following exposure at $900{ }^{\circ} \mathrm{C}$ for $1000 \mathrm{~h}$ showing the dark BSE contrast phase observed in the vicinity of grain boundaries and corresponding EDX elemental distribution maps for $\mathrm{Ti}, \mathrm{Nb}, \mathrm{Zr}$ and $\mathrm{O}$.

\subsection{Microstructural Condition at 1000 and $900^{\circ} \mathrm{C}$}

XRD data obtained from each alloy following exposure at 1000 and $900{ }^{\circ} \mathrm{C}$ was very similar, as shown in Figure 6. Reflections consistent with a bcc phase were seen in all cases and the refined lattice parameters obtained from fitting with TOPAS academic are presented in Table 2. In all cases, these lattice parameters were essentially the same as those obtained from the solution heat treated condition. In the patterns corresponding to Alloys 5540, 7025 and 8510 , some of the higher angle peaks in the patterns exhibited asymmetric profiles, similar to those seen in the solutioned condition in Figure 2. As before, the occurrence of this asymmetry suggested the presence of another phase. However, the lack of any discernible contrast in the BSE images, Figure 4, implied that this secondary phase was extremely small and thus likely to have formed on cooling. As such, this secondary phase was not in equilibrium at temperatures above $900{ }^{\circ} \mathrm{C}$ and was not investigated further.

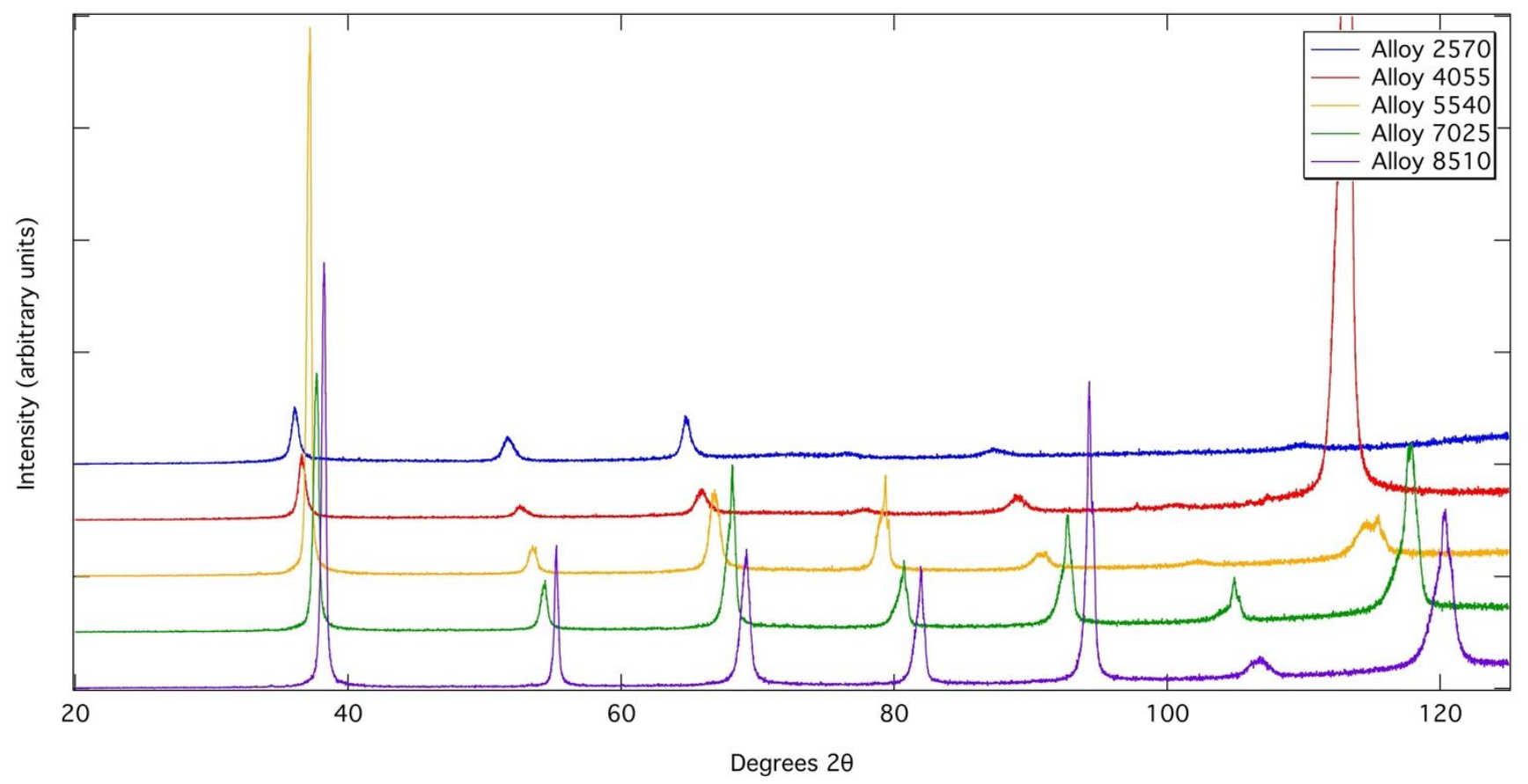

Figure 6. X-ray diffraction patterns acquired from each of the alloys following exposure at $900{ }^{\circ} \mathrm{C}$ for $1000 \mathrm{~h}$.

\subsection{Microstructures Formed at $700{ }^{\circ} \mathrm{C}$}

As mentioned above, many of the alloys contained multiple phases following $1000 \mathrm{~h}$ exposure at $700{ }^{\circ} \mathrm{C}$ and the microstructures formed varied depending on the $\mathrm{Nb}: \mathrm{Zr}$ ratio of the material, Figure 4. To provide a more detailed characterisation of the different phases present in this condition, TEM foils were extracted from Alloys 2570, 4055 and 5540. 
Following exposure at $700{ }^{\circ} \mathrm{C}$, Alloy 2570 exhibited a uniform BSE contrast across the microstructure, Figure 4, consistent with the solution heat treated condition. Higher resolution characterisation of material extracted from a grain interior produced corroborating results, with no evidence of a secondary phase in either the STEM high angle annular dark field (HAADF) image or in the corresponding EDX elemental distribution maps, Figure 7. An electron diffraction pattern obtained from this region also contained reflections consistent with a single bcc structure and, thus, it would appear that this composition lies within a single phase field at $700{ }^{\circ} \mathrm{C}$.
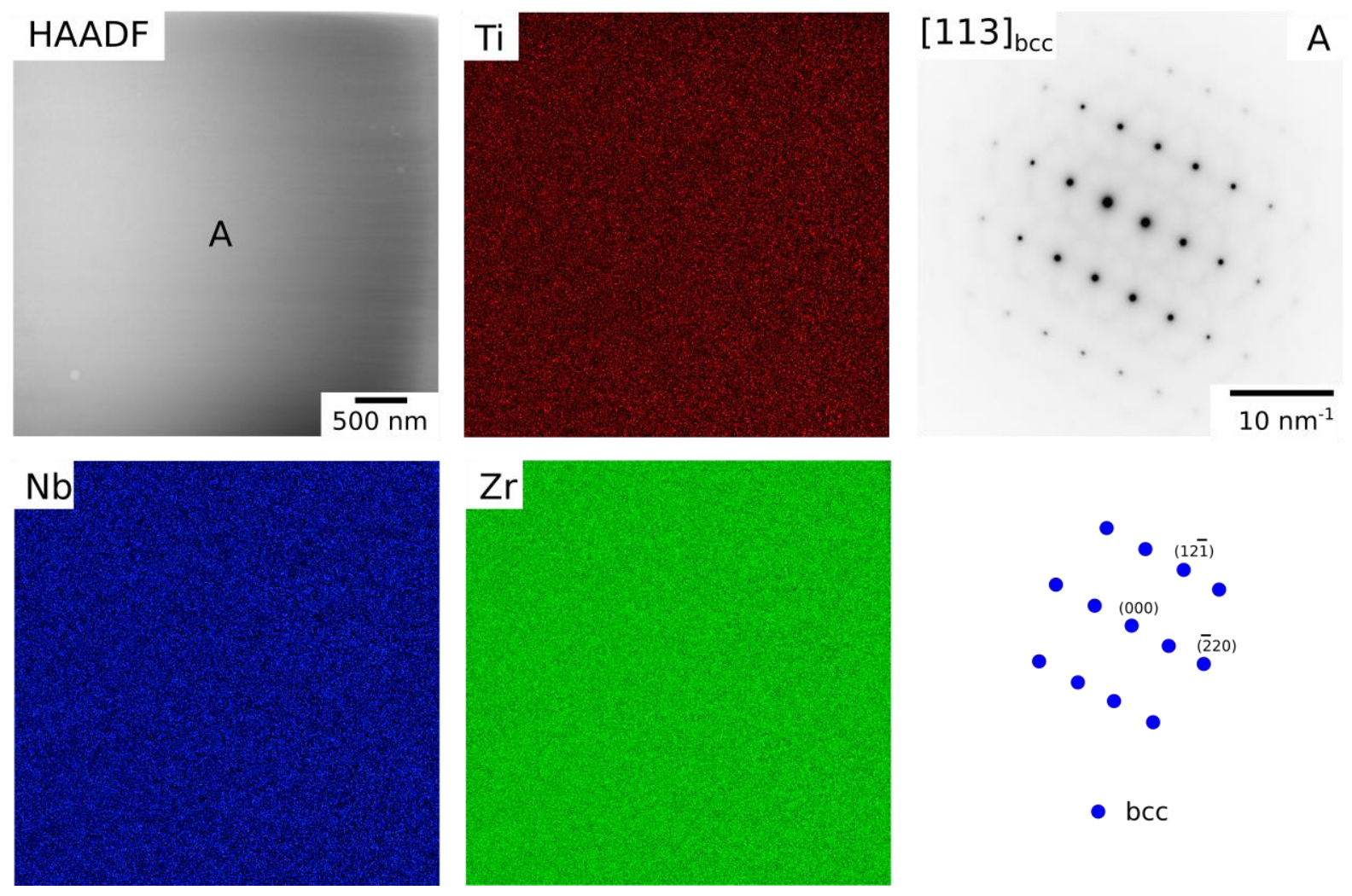

Figure 7. TEM HAADF image and STEM EDX elemental distribution maps for Ti, $\mathrm{Nb}$ and $\mathrm{Zr}$ acquired for Alloy 2570 (Ti-25Nb-70Zr at.\%) following exposure at $700{ }^{\circ} \mathrm{C}$ for $1000 \mathrm{~h}$. An SADP corresponding to the region labelled A contains bcc reflections consistent with the [113] zone axis, as shown in the related key diagram below.

The microstructure of Alloy 4055 following exposure at $700{ }^{\circ} \mathrm{C}$ exhibited a two-phase intragranular microstructure consisting of a matrix phase within which rounded light BSE contrast precipitates were distributed, Figure 4. The light BSE contrast phase was also observed along the grain boundaries, bisected by lamellae of an additional dark BSE contrast phase that was only present at the grain boundaries. HAADF images acquired from the grain interior of Alloy 4055, Figure 8, comprised a matrix phase, denoted A, within which rounded precipitates of a lighter HAADF contrast, labelled B, resided. The corresponding EDX elemental distribution maps showed phase A to be enriched in $\mathrm{Zr}$ compared to the precipitates, phase $\mathrm{B}$, which were enriched in $\mathrm{Nb}$ and to a lesser extent in Ti. Quantitative EDX measurements, given in Table 3, indicated that Ti partitioning was not significant to either phase. Selected area diffraction patterns (SADPs) from these two phases, which were acquired at the same tilt angle, are also presented in Figure 8. Both SADPs corresponded to a bcc crystal structure, with similar lattice parameters and orientations, suggesting that the two phases may be aligned in a cube-cube relationship. Faint reciprocal lattice streaking along the $\langle 112\rangle_{\text {bcc }}$ was observed in the Zr-rich phase A. Previously, this feature has been associated with the presence of an incommensurate omega 
phase $[24,25]$. However, as this phase is known to form on cooling at lower temperatures than those of interest in this study, no further attempt to confirm the identity of this phase was made here.
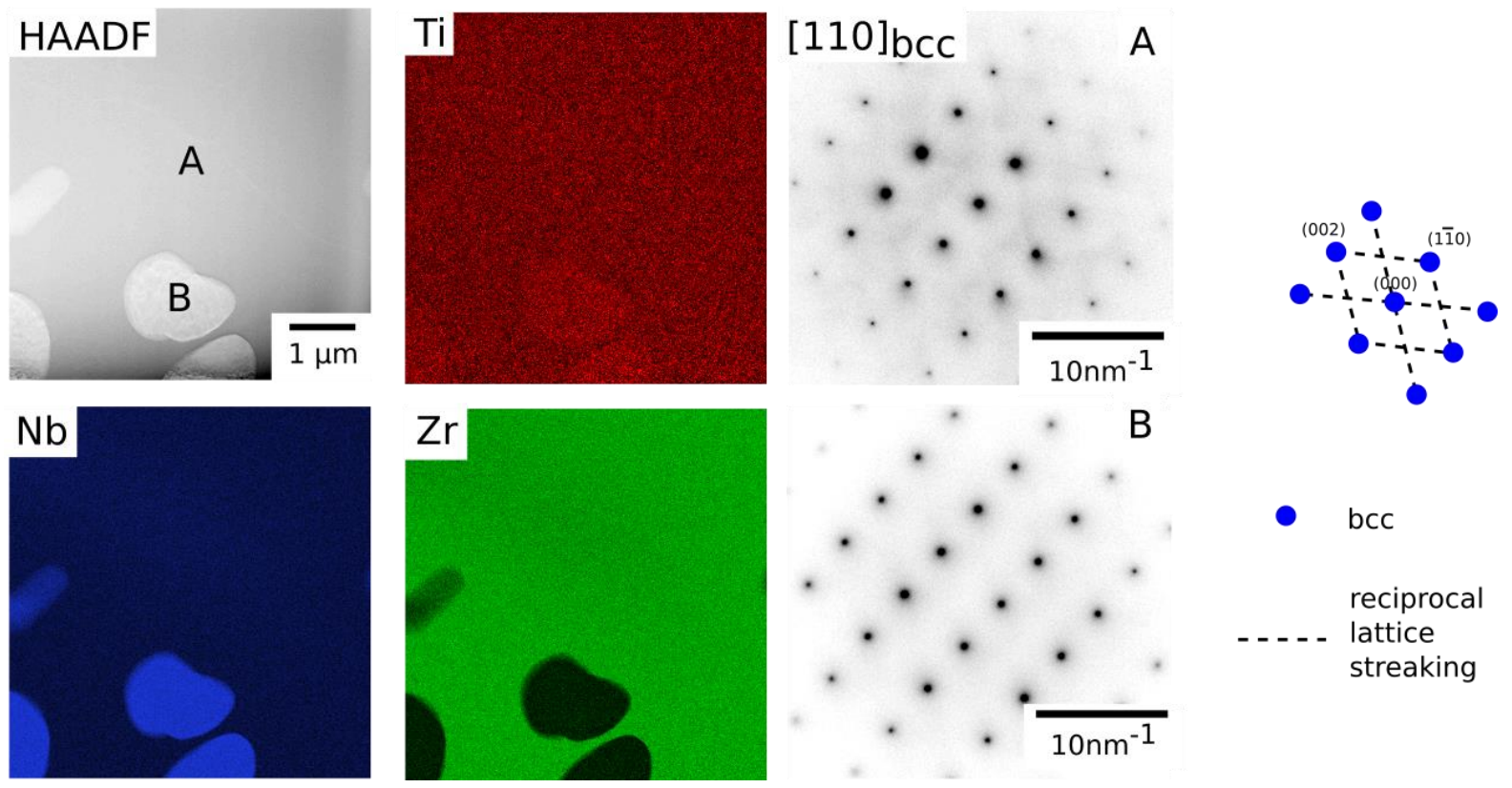

- bcc

reciprocal

lattice streaking

Figure 8. TEM HAADF image and STEM EDX elemental distribution maps for Ti, $\mathrm{Nb}$ and $\mathrm{Zr}$ acquired for Alloy 4055 (Ti-40Nb-55Zr at.\%) following exposure at $700{ }^{\circ} \mathrm{C}$ for $1000 \mathrm{~h}$. An SADP from a $\mathrm{Zr}$ rich region (A) and $\mathrm{Nb}$ rich region $(\mathbf{B})$ showed only bcc reflections consistent with the [110] zone axis. The related key diagram is shown to the right.

Table 3. Quantitative STEM EDX measurements of the phases present in Alloys 2570, 4055 and 5540 following exposure at $700{ }^{\circ} \mathrm{C}$ for $1000 \mathrm{~h}$.

\begin{tabular}{cccc}
\hline Alloy & Ti (at.\%) & Nb (at.\%) & Zr (at.\%) \\
\hline $\begin{array}{ccc}\text { Alloy 2570 } \\
\text { Phase A }\end{array}$ & $4.7 \pm 0.1$ & $23.4 \pm 0.1$ & $71.8 \pm 0.1$ \\
\hline Alloy 4055 & & & \\
Phase A & $4.3 \pm 0.1$ & $28.6 \pm 1.8$ & $67.1 \pm 1.8$ \\
Phase B & $4.8 \pm 0.2$ & $82.7 \pm 0.2$ & $12.5 \pm 0.3$ \\
\hline Alloy 5540 & & & \\
Phase A & $4.1 \pm 0.1$ & $26.9 \pm 0.2$ & $12.5 \pm 1.0$ \\
Phase B & $4.5 \pm 0.5$ & $83.0 \pm 0.5$ & $97.6 \pm 0.2$ \\
Phase C & $1.3 \pm 0.1$ & $1.1 \pm 0.2$ &
\end{tabular}

The BSE images of Alloys 5540 and 7025 following exposure at $700{ }^{\circ} \mathrm{C}$ revealed very similar microstructures, consisting of a light and mid-grey BSE contrast lamellae throughout the grain interiors, Figure 4 . In addition, a dark BSE contrast phase was observed decorating the grain boundaries in both alloys. This phase extended from the grain boundaries up to $10 \mu \mathrm{m}$ into the grain interior in lamellar morphologies with the brighter BSE contrast phases. To further characterise this microstructure, an electron transparent foil containing all three features was extracted from a grain boundary region of Alloy 5540. A HAADF image and corresponding EDX elemental distribution maps obtained from this foil are shown in Figure 9. 

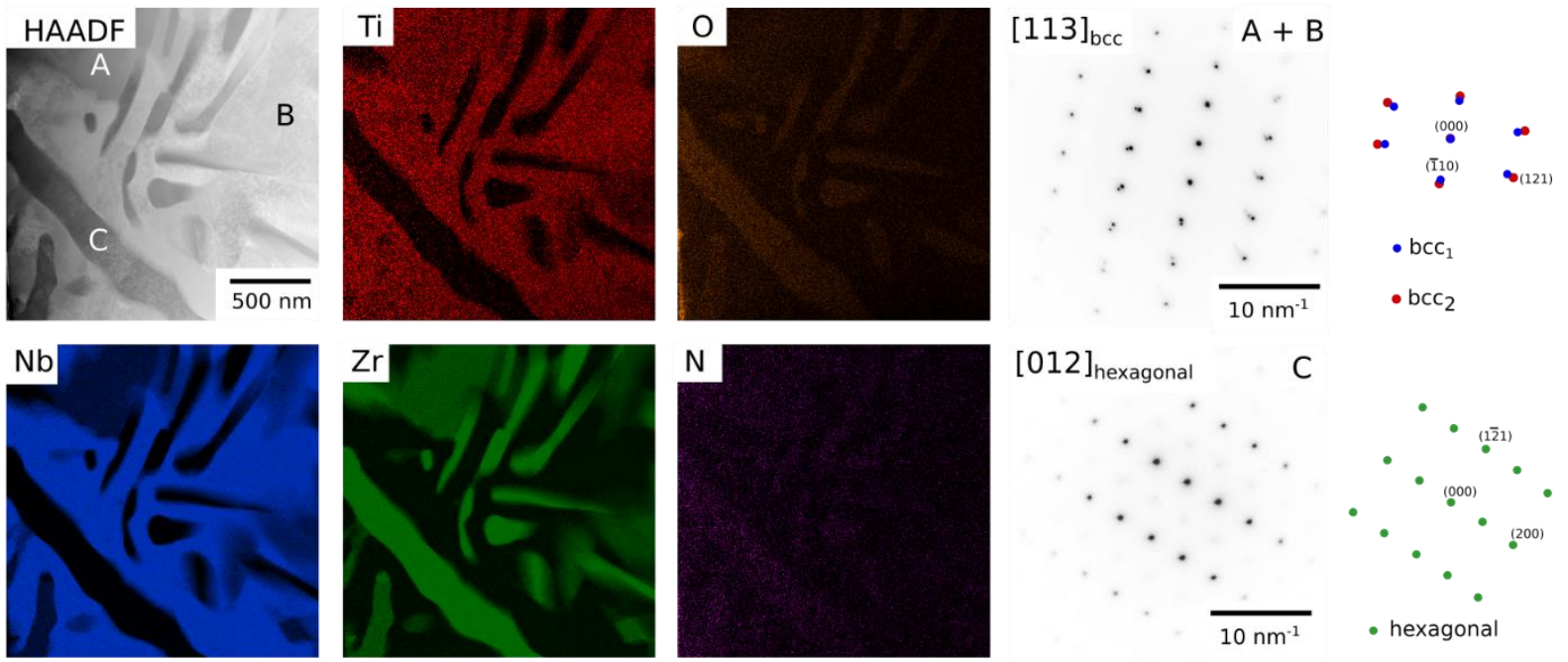

Figure 9. TEM HAADF image and STEM EDX elemental distribution maps for Ti, Nb, Zr, O and N acquired for Alloy 5540 (Ti-55Nb-40Zr at.\%) following exposure at $700{ }^{\circ} \mathrm{C}$ for $1000 \mathrm{~h}$. Right-an SADP from a region containing both the $\mathrm{Zr}$ rich region $(\mathbf{A})$ and $\mathrm{Nb}$ rich region $(\mathbf{B})$ showed only bcc reflections whilst that from region $(\mathbf{C})$ contained hexagonal reflections. Key diagrams are included for both SADPs.

Within the matrix regions, evidence of two phases could be seen, labelled A and B in Figure 9. These features were enriched in $\mathrm{Nb}$ and in $\mathrm{Zr}$, respectively, with the level of $\mathrm{Ti}$ partitioning relatively even. Quantitative analysis of the EDX measurements are given in Table 3 and these compositions showed phases A and B were very similar to those found in Alloy 4055. Electron diffraction patterns taken from the matrix material indicated that phases A and B both had bcc crystal structures and appear to be aligned in a cube-cube orientation. However, there was a more pronounced difference in the lattice parameters between the bcc phases in this condition than was implied by the asymmetric peak profiles for the same alloy following exposure at $900{ }^{\circ} \mathrm{C}$.

In addition to the light HAADF contrast matrix phase, features with dark HAADF contrast were also observed delineating the grain boundaries and as high aspect ratio intragranular precipitates. EDX data from these features, labelled as phase $C$, found them to be highly enriched in $\mathrm{Zr}$ and deficient in both $\mathrm{Ti}$ and $\mathrm{Nb}$. Quantitative analysis of these data, given in Table 3, indicated that Phase $C$ was nearly pure $Z r$ and contained only $~ 1$ at. $\%$ of both $\mathrm{Nb}$ and Ti. Further examination of the EDX data indicated that this phase was slightly enriched in $\mathrm{O}$ when compared to phases $\mathrm{A}$ and $\mathrm{B}$. While quantitative measurements of $\mathrm{O}$ content are not reliable with EDX, the $\mathrm{O}$ enrichment was not high enough to imply the formation of an oxide phase. Given this composition and the allotropic nature of $\mathrm{Zr}$, it is unsurprising that the SADPs obtained from this region, such as that shown in Figure 9, were consistent with a hexagonal crystal structure with lattice parameters similar to those of hcp $\alpha-Z$ r.

The microstructure produced in Alloy 8510 following exposure at $700{ }^{\circ} \mathrm{C}$ was similar to that observed following exposure at higher temperatures, comprising grains with an even BSE contrast to the resolution of the microscope.

The XRD data taken from each of the alloys following exposure at $700{ }^{\circ} \mathrm{C}$ can be seen in Figure 10. In each pattern, reflections corresponding to one or two bcc phases were observed, with no other reflections visible above the background levels. No reflections corresponding to the hexagonal phase were evident in the XRD data, which is likely due to its low volume fraction and presence only in regions near the grain boundaries. As was observed in the TEM data, the distinct sets of bcc reflections present in the data for Alloys 4055, 5540 and 7025 had significantly different lattice parameters of $\sim 3.3$ and $\sim 3.5 \AA$, respectively. The TEM SADPs in Figure 8 indicated that the $\mathrm{Zr}$-rich bcc phase had larger 
lattice parameters than the $\mathrm{Nb}$-rich bcc phase. Within the data, asymmetric peaks were present as seen at higher exposure temperatures in Alloys 4055, 5540, 7025 and 8510.

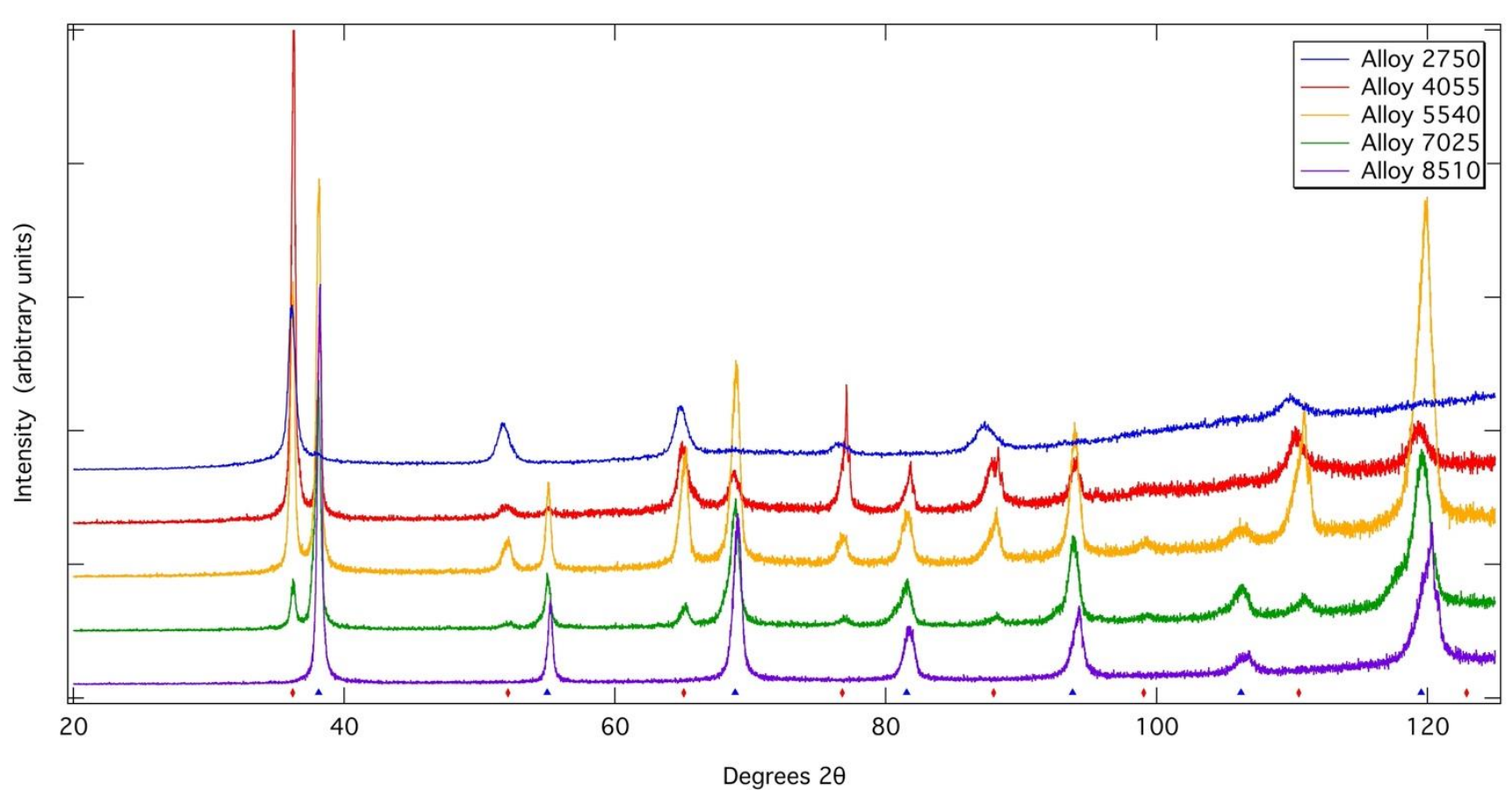

Figure 10. X-ray diffraction patterns acquired from each of the alloys following exposure at $700{ }^{\circ} \mathrm{C}$ for $1000 \mathrm{~h}$. Tick marks indicate the positions of bcc phases.

\section{Discussion}

All of the alloys considered in this study are located within a single phase field when exposed at temperatures above $1000^{\circ} \mathrm{C}$, consistent with existing phase diagrams. However, discrepancies between the predicted and observed phases occurred following exposures at 900 and $700{ }^{\circ} \mathrm{C}$. At $900{ }^{\circ} \mathrm{C}$, all of the alloys were expected to reside in a single bcc phase field, except Alloy 5540 which was predicted to lie just within the bcc + bcc region, Figure 1. Despite this, decomposition of the alloys was not observed at $900{ }^{\circ} \mathrm{C}$, suggesting that a single bcc phase field extended across the entirety of the compositional space investigated here. Therefore, it would appear that the bcc + bcc solvus is lower than shown by Doi et al. [17] and more consistent with the prediction of Lin et al. [20] and Kumar et al. [19] that show Alloy 5540 to be right on the edge of the phase field at $900{ }^{\circ} \mathrm{C}$. The results here suggest that the position of the solvus is such that the composition of Alloy 5540 was just outside the miscibility gap at $900{ }^{\circ} \mathrm{C}$.

At $700{ }^{\circ} \mathrm{C}$, the published isothermal sections suggest that Alloys 4055, 5540 and 7025 should all be within the bcc + bcc region. The experimental observations made in this study were in good agreement with this, as two phases were observed within the grain interiors of these alloys, both of which had bcc structures. However, an additional dark contrast Zr-rich grain boundary phase was present in all three alloys, Figure 4, which was determined to have a hexagonal crystal structure, Figure 9, with lattice parameters consistent with $\alpha$-Zr. The presence of grain boundary phases may also be facilitated by the lower energy required for nucleation on the boundaries. This phase was also slightly enriched in $\mathrm{O}$. The presence of a third $\mathrm{Zr}$-rich phase is inconsistent with the predicted phase diagrams, however, these ternary diagrams do not consider the influence of $\mathrm{O}$.

The dual bcc phase field has been proposed to be the precursor to forming the bcc $+\mathrm{B} 2$ microstructure observed in RSAs $[8,10,13]$. In RSAs, quenched microstructures consist of aligned bcc and B2 phases with small lattice parameter misfits of $\sim 1 \%$, leading to a cube-cube arrangement and cuboidal precipitate morphologies [3]. This was also observed 
to be the case in the Ta-Ti-Zr constituent system, which exhibited a nanoscale cuboidal precipitate morphology following quenching and a blocky morphology following long duration thermal exposure at $700{ }^{\circ} \mathrm{C}$, with a misfit of $2.6-2.7 \%$ between the bcc phases [10]. However, here, following long duration exposure at $700{ }^{\circ} \mathrm{C}$, precipitates with rounded and curved lamellar morphologies were observed in alloys from the Ti-Nb-Zr system, Figure 4. In depth analysis of these intragranular microstructures using electron diffraction revealed that both the matrix and precipitates had bcc structures and were aligned in a cube-cube relationship, Figures 8 and 9. However, in contrast to RSAs and the Ta-TiZr system, both electron and X-ray diffraction data showed that there was a significant difference in lattice parameters, which is most clearly visible in Figure 9. Using Equation (1) below [26], where $\delta$ is misfit and $a_{1}$ and $a_{2}$ are the lattice parameters the two phases, the misfit between the two bcc phases following exposure at $700{ }^{\circ} \mathrm{C}$ was found to be between 4.7 and $5.0 \%$. This misfit is far greater than that in either RSAs or the Ta-Ti-Zr system and is likely to prevent coherent precipitate-matrix interfaces. Consequently, the effect of lattice symmetry on precipitate morphology will be reduced, leading to the more rounded morphologies observed here. Large misfit between phases is undesirable in alloys for use at high temperature, as it encourages precipitate coarsening and the incoherent interface can limit the effect of precipitate and order hardening mechanisms. To rectify this, further compositional modifications within the Ti-Nb-Zr system or with other elements may produce bcc phases with a lower misfit. The Ti content in both bcc phases was very similar, Table 1, and therefore the difference in lattice parameter must be associated with the variation of $\mathrm{Nb}$ and $\mathrm{Zr}$. $\mathrm{Zr}$ is known to have a strong effect on the lattice parameter [23], whilst dependence on the $\mathrm{Nb}$ content is less significant [27]. Therefore, it may be of benefit to design RSAs with a less marked Zr variation across the miscibility gap.

$$
\delta=2\left(\frac{a_{1}-a_{2}}{a_{1}+a_{2}}\right)
$$

Whilst phase diagrams document the thermodynamically stable phases, they do not always account for metastable phases or the route of phase formation. The proposed microstructural formation route of the fine-scale two-phase features typical of RSAs is that of a spinodal decomposition. This process proceeds by the decomposition of a single phase bcc, which is thermodynamically stable at high temperature, into two bcc phases upon cooling, one of which then undergoes a subsequent ordering to produce a mixture of $\mathrm{B} 2$ and bcc phases $[8,10,13]$. The presence of a miscibility gap within the Ti-Nb-Zr system does not necessarily mean the system exhibits spinodal behaviour as strain energy can inhibit decomposition occurring during cooling [28,29]. Consequently, the high misfit between the two product bcc phases in this system may be sufficient to suppress spinodal decomposition.

However, asymmetric peak profiles were observed in the XRD profiles of Alloys 4055, 5540,7025 and 8510 following heat treatment, which could be rationalised by fitting with two bcc phases of very close lattice parameter in TOPAS Academic. This could suggest that a spinodal breakdown occurred during cooling from the heat treatment temperatures to form two bcc phases of very similar lattice parameters. However, other phases, such as the omega phase in Ti-rich alloys can also cause similar asymmetric peak profiles. Despite these asymmetries in the $\mathrm{XRD}$ peak profiles, no evidence of a two-phase nanoscale microstructure could be observed within the resolution of the imaging used $(\sim 10 \mathrm{~nm})$, even following slow cooling from above the solvus temperature. Though it should be noted that the close atomic numbers of $\mathrm{Nb}$ and $\mathrm{Zr}$ give low compositional contrast. In addition, the equilibrium phase compositions determined from the samples exposed at $700{ }^{\circ} \mathrm{C}$ suggest that, at this temperature, Alloy 8510 lies outside of the miscibility gap and so it is not considered likely that this alloy could undergo a spinodal transformation. As such, from the data presented here, it is not possible to conclusively confirm whether or not spinodal decomposition occurs in this system. Given that spinodal decomposition has been shown to occur in similar alloys derived from the Ta-Ti-Zr system, it may be inferred that care must be taken 
in balancing the $\mathrm{Nb}$ and Ta contents of RSAs to ensure that the desired level precipitation is achieved.

\section{Summary}

The formation of the typical fine-scale two-phase bcc+B2 RSA microstructures is believed to a consequence of the $\mathrm{Ta}-\mathrm{Zr}$ or $\mathrm{Nb}-\mathrm{Zr}$ miscibility gaps. However, whether microstructures similar to those in RSA could be produced through the interactions between $\mathrm{Nb}$ and $\mathrm{Zr}$ remained unclear. To address this issue, here, the $\mathrm{Nb}-\mathrm{Zr}$ miscibility gap has been investigated through microstructural analysis of a systematic series of alloys within the $\mathrm{Nb}-\mathrm{Ti}-\mathrm{Zr}$ system following quenching from solution heat treatment and long duration thermal exposures at 1000,900 and $700{ }^{\circ} \mathrm{C}$.

All of the alloys remained within the single bcc phase field during exposures at temperatures of $900{ }^{\circ} \mathrm{C}$ and above. Following exposure at $700{ }^{\circ} \mathrm{C}$, Alloys 4055, 5540 and 7025 exhibited a coarse two-phase intragranular microstructure comprising Zr-rich and Nbrich bcc phases. The misfit between these phases was found to be high, with values between 4.7 and 5.0\%. An additional $\mathrm{Zr}$-rich hexagonal phase, which also exhibited elevated $\mathrm{O}$ levels, occurred in the near grain boundary regions and was consistent with the $\alpha-\mathrm{Zr}$ phase.

No clear evidence of a spinodal decomposition, nor the nano-scale cuboidal microstructures seen in RSAs or the Ta-Ti-Zr and Al-Ta-Ti-Zr systems, were observed in the Ti-Nb-Zr alloys studied. While it is not possible to conclusively confirm whether a spinodal decomposition occurs in this system, this observation suggests that the $\mathrm{Nb}-\mathrm{Zr}$ miscibility gap does not contribute as significantly to the formation of RSA microstructures as the interactions produced by the Ta-Zr miscibility gap.

Author Contributions: Conceptualization, N.G.J. and T.E.W.; Methodology, N.G.J. and T.E.W.; Formal Analysis, T.E.W.; Investigation, G.J.W., T.E.W. and E.J.P.; Resources, N.G.J.; Writing-Original Draft Preparation, T.E.W. and N.G.J.; Writing-Review and Editing, H.J.S., G.J.W. and E.J.P.; Visualization, T.E.W.; Supervision, N.G.J.; Project Administration, N.G.J.; Funding Acquisition, H.J.S. and N.G.J. All authors have read and agreed to the published version of the manuscript.

Funding: T.E.W., N.G.J. and H.J.S. would like to acknowledge support from the EPSRC/Rolls-Royce Strategic Partnership (EP/M005607/1). The support of the Henry Royce Institute for access to the FEI Talos electron microscope at Royce@Manchester (EP/R00661X/1, EP/S019367/1, EP/P025021/1 and EP/P025498/1) is also gratefully acknowledged, as is the same funding for EJP's Research Area Lead position at the Institute.

Institutional Review Board Statement: Not applicable.

Informed Consent Statement: Not applicable.

Data Availability Statement: The underlying research data can be accessed from The University of Cambridge repository (https:/ / doi.org/10.17863/CAM.72659, accessed on 29 July 2021).

Acknowledgments: Preparation of the TEM sample was performed via FIB-liftout by G. West at the WMG, University of Warwick.

Conflicts of Interest: The authors declare no conflict of interest.

\section{References}

1. Senkov, O.; Isheim, D.; Seidman, D.; Pilchak, A. Development of a Refractory High Entropy Superalloy. Entropy 2016, $18,102$. [CrossRef]

2. Miracle, D.B.; Tsai, M.-H.; Senkov, O.N.; Soni, V.; Banerjee, R. Refractory high entropy superalloys (RSAs). Scr. Mater. 2020, 187, 445-452. [CrossRef]

3. Jensen, J.K.; Welk, B.A.; Williams, R.E.A.; Sosa, J.M.; Huber, D.E.; Senkov, O.N.; Viswanathan, G.B.; Fraser, H.L. Characterization of the microstructure of the compositionally complex alloy Al1Mo0.5Nb1Ta0.5Ti1Zr1. Scr. Mater. 2016, 121, 1-4. [CrossRef]

4. Miracle, D.B.; Senkov, O.N. A critical review of high entropy alloys and related concepts. Acta Mater. 2017, 122, 448-511. [CrossRef]

5. Senkov, O.N.; Jensen, J.K.; Pilchak, A.L.; Miracle, D.B.; Fraser, H.L. Compositional variation effects on the microstructure and properties of a refractory high-entropy superalloy AlMo0.5NbTa0.5TiZr. Mater. Des. 2018, 139, 498-511. [CrossRef] 
6. Gorsse, S.; Couzinié, J.-P.; Miracle, D.B. From high-entropy alloys to complex concentrated alloys. Comptes Rendus Phys. 2018, 19, 721-736. [CrossRef]

7. Soni, V.; Senkov, O.N.; Gwalani, B.; Miracle, D.B.; Banerjee, R. Microstructural Design for Improving Ductility of An Initially Brittle Refractory High Entropy Alloy. Sci. Rep. 2018, 8, 8816. [CrossRef]

8. Soni, V.; Gwalani, B.; Alam, T.; Dasari, S.; Zheng, Y.; Senkov, O.N.; Miracle, D.; Banerjee, R. Phase inversion in a two-phase, BCC+B2, refractory high entropy alloy. Acta Mater. 2020, 185, 89-97. [CrossRef]

9. Soni, V.; Gwalani, B.; Senkov, O.N.; Viswanathan, B.; Alam, T.; Miracle, D.B.; Banerjee, R. Phase stability as a function of temperature in a refractory high-entropy alloy. J. Mater. Res. 2018, 33, 3235-3246. [CrossRef]

10. Whitfield, T.E.; Pickering, E.J.; Christofidou, K.A.; Jones, C.N.; Stone, H.J.; Jones, N.G. Elucidating the microstructural development of refractory metal high entropy superalloys via the Ti-Ta-Zr constituent system. J. Alloys Compd. 2020, 818, 152935. [CrossRef]

11. Whitfield, T.E.; Pickering, E.J.; Talbot, C.E.; Jones, C.N.; Stone, H.J.; Jones, N.G. Observation of a refractory metal matrix containing Zr-Ti-rich precipitates in a Mo0.5NbTa0.5TiZr high entropy alloy. Scr. Mater. 2020, 180, 71-76. [CrossRef]

12. Whitfield, T.E.; Pickering, E.J.; Owen, L.R.; Senkov, O.N.; Miracle, D.B.; Stone, H.J.; Jones, N.G. An assessment of the thermal stability of refractory high entropy superalloys. J. Alloys Compd. 2020, 857, 157583. [CrossRef]

13. Whitfield, T.E.; Pickering, E.J.; Owen, L.R.; Jones, C.N.; Stone, H.J.; Jones, N.G. The effect of Al on the formation and stability of a BCC - B2 microstructure in a refractory metal high entropy superalloy system. Materialia 2020, 13, 100858. [CrossRef]

14. Whitfield, T.E.; Stone, H.J.; Jones, C.N.; Jones, N.G. Microstructural Degradation of the AlMo0.5NbTa0.5TiZr Refractory Metal High-Entropy Superalloy at Elevated Temperatures. Entropy 2021, 23, 80. [CrossRef] [PubMed]

15. Okamoto, H. Ta-Zr (Tantalum-Zirconium). J. Phase Equilibria 1996, 17, 555. [CrossRef]

16. Abriata, J.P.; Bolcich, J.C. The Nb-Zr (Niobium-Zirconium) System. Bull. Alloy Phase Diagr. 1982, 3, 34-44. [CrossRef]

17. Doi, T.; Ishida, H.; Umezawa, T. Study of Nb-Zr-Ti Phase Diagram (Studies of a Hard Superconductor, II). J. Jpn. Inst. Met. Mater. 1996, 30, 139-145. [CrossRef]

18. Doi, T.; Kitada, M.; Ishida, F. Isothermal Phase Diagram of the Nb-Zr-Ti Ternary System at $570{ }^{\circ} \mathrm{C}$ (Supplement). J. Jpn. Inst. Met. Mater. 1968, 32, 684-685. [CrossRef]

19. Kumar, K.C.H.; Wollants, P.; Delaey, L. Thermodynamic assessment of the Ti-Zr system and calculation of the Nb-Ti-Zr phase diagram. J. Alloys Compd. 1994, 206, 121-127. [CrossRef]

20. Lin, L.; Delaey, L.; Van Der Biest, O.; Wollants, P. Calculation of Isothermal Sections of Three Ternary Ti-Zr-X Systems. Scr. Mater. 1996, 34, 1411-1416. [CrossRef]

21. Tokunaga, T.; Matsumoto, S.; Ohtani, H.; Hasebe, M. Thermodynamic Calculation of Phase Equilibria in the Nb-Ni-Ti-Zr Quaternary System. Mater. Trans. 2007, 48, 89-96. [CrossRef]

22. Hu, Y.-M.; Liu, X.-D.; Guo, N.-N.; Wang, L.; Su, Y.-Q.; Guo, J.-J. Microstructure and mechanical properties of NbZrTi and NbHfZrTi alloys. Rare Met. 2019, 38, 840-847. [CrossRef]

23. Pang, E.L.; Pickering, E.J.; Baik, S.I.; Seidman, D.N.; Jones, N.G. The effect of zirconium on the omega phase in Ti-24Nb-[0-8]Zr (at.\%) alloys. Acta Mater. 2018, 153, 62-70. [CrossRef]

24. Bennett, J.M.; Pickering, E.J.; Barnard, J.S.; Rugg, D.; Stone, H.J.; Jones, N.G. Observation of a new B2 structured phase in Ti-15Mo (wt\%). Mater. Charact. 2018, 142, 523-530. [CrossRef]

25. Collings, E.W. The Physical Metallurgy of Titanium Alloys; American Society for Metals: Russell, OH, USA, 1984.

26. Reed, R.C. The Superalloys: Fundamentals and Applications; Fundamentals and Applications; Cambridge University Press: Cambridge, UK, 2006; pp. 33-120.

27. Moreno, J.J.G.; Bönisch, M.; Panagiotopoulos, N.T.; Calin, M.; Papageorgiou, D.G.; Gebert, A.; Eckert, J.; Evangelakis, G.A.; Lekka, C.E. Ab-initio and experimental study of phase stability of Ti-Nb alloys. J. Alloys Compd. 2017, 696, 481-489. [CrossRef]

28. Rundman, K.B.; Hilliard, J.E. Early stages of spinodal decomposition in an aluminium-zinc alloy. Acta Metall. 1967, 15, 1025-1033. [CrossRef]

29. Cahn, J.W. On spinodal decomposition. Acta Metall. 1961, 9, 795-801. [CrossRef] 